\title{
Effect of PLISSIT Model Sexual Counseling Program on Sexual Quality of Life for Postpartum Women
}

\author{
Eman Mohammed Abdelhakm ${ }^{1}$, Amira Refaat Said ${ }^{1}$, Doaa Mohamed Sobhy Elsayed ${ }^{2}$ \\ ${ }^{1}$ Obstetrics and Woman's Health Nursing, Faculty of Nursing, Benha University, Benha, Egypt \\ ${ }^{2}$ Community Health Nursing, Faculty of Nursing, Benha University, Benha, Egypt
}

\section{Email address:}

Amira.refaat21@yahoo.com(A. R. Said)

\section{To cite this article:}

Eman Mohammed Abdelhakm, Amira Refaat Said, Doaa Mohamed Sobhy Elsayed. Effect of PLISSIT Model Sexual Counseling Program on Sexual Quality of Life for Postpartum Women. American Journal of Nursing Science. Vol. 7, No. 2, 2018, pp. 63-72. doi: 10.11648/j.ajns.20180702.14

Received: February 19, 2018; Accepted: March 5, 2018; Published: March 24, 2018

\begin{abstract}
Sexual changes after childbirth between couples are an important factor in creating a sense of satisfaction which effects on their quality of life. Aim: to evaluate effect of PLISSIT Model sexual counseling program on sexual quality of life for postpartum women. Research design: A quasi experimental design. Setting: The study was conducted in Obstetrics and Gynecological Outpatient Clinic at Benha University Hospital. Sample: A purposive sample of all admitted postpartum women for a period of 6 months (110) woman. Tools: Three tools were used I): An interviewing questionnaire. II): Arizona Sexual Experience Scale. III) The sexual quality of life-female questionnaire. Results: showed that the mean age of studied women were $25.02 \pm 4.47$ years, $85.5 \%$ of women did not receive information about sexuality, $72.3 \%$ suffered from pain during intercourse after labor, $63.6 \%$ of them returned to sexual relation six week after labor. Only $13.6 \%$ of women had good total sexual quality of life before PLISSIT model counseling program, which increased to $44.5 \%$ after program. there were highly statistically significant differences between women regarding Arizona Sexual Experiences Scale and all sexual quality of life items before and after sexual counseling program $(\mathrm{p}<0.001)$. Conclusion: the PLISSIT model counseling program had a significant effect on the improvement of the women' sexual quality of life. Recommendations: Establish strategies to facilitate the women's understanding and support sexual quality of life through apply this study on a large sample at outpatient clinics.
\end{abstract}

Keywords: PLISSIT Model Counseling Program, Postpartum Women, Quality of Sexual Life

\section{Introduction}

Postpartum is a critical period in a woman's life, which involves significant physical, hormonal, psychological, social, and cultural changes that may influence her own sexuality as well as the health of a couple's sexual relationship. It is recognized that women frequently experience problems immediately following birth but less extensively diagnosed which lead to persist long after postpartum and conventionally ends [17], 97 from 674 women (14\%) of them reported complaints of dyspareunia, irrespective of the trial management. More recently, a survey of over 2000 National Childbirth Trust members revealed that a quarter of participants needed extra than six weeks for their perineum to regain 'normal' again, and $17 \%$ reported problems during sexual relation [13].
The sexual health of women during postpartum period can be changed by many conditions. These include age, level of education, the years of marriage or the relationship with their husbands, sexual condition before and during pregnancy, type of delivery, breast-feeding, psychological troubles and perennial lacerations [15]; [19]. Fatigue, sleeplessness, some stressors such as baby care which is highly time consuming, hormonal changes (reduction of estrogen \& progesterone level and then elevation of prolactin) and also modifications in the woman's body image during the postpartum period are motives for reduced interest in sexual life and the reduced frequency of sexual relations [7].

Most women attempt to return to their sexual relations within 8 to 12 weeks after labor, but in some cases extend to a year to return to normal sexual intercourse as they used to before pregnancy. Postpartum challenges related to sexual intercourse can continue for three months on the average (1 
to 11 months). Many women after labor and during postpartum period experience dyspareunia due to reduction in secretions of the vagina resulting from a low level of estrogen. Sexual desire decreased in both breastfeeding women and who's suffered from dyspareunia due to disturbances in hormonal levels and vaginal dryness [1].

Another factor that has important role in reducing sexual desire and adversely affect the intimacy of the couple and sexual quality of life is new born responsibilities and the parental role, as well as changes in body image and the desexualized figure of woman, cultivated by community. In addition to fear of pain sensation during the intercourse or becoming pregnant again may cause anxiety and disturbances in the sexual female sexuality [34]; [20].

Nursing care plan for counseling postpartum sexual problems can achieve from the PLISSIT Model which provides a comprehensive framework. This model was developed by [4]. And it deals with sexual issues individually In this model, women are permitted to discuss freely about their sexual troubles, limited information is given for them about their needs, and then are provided to solve their sexual problem and enhance better sexual quality of life. Finally, special therapy is provided for those require further intervention [26] So, This PLISSIT is an acronym includes four levels of intervention, ranging from basic to complex these include P-Permission, LI-Limited Information, SSSpecific Suggestions and IT-Intensive Therapy. By applying the first three stages of this model, 80 to $90 \%$ of sexual problems can be solved [10].

Nurses play an crucial role in counseling postpartum sexual health which has little attention in Egypt and encounters difficulties when discussed by the health care providers to strengthen the sexual health of the woman, encourage the expression of sexual difficulties, define the causes and characteristics of sexual problems and implement interventions regarding problems defined in order to attain better quality of life. Nurses can design and implement various programs to the sexual health of a woman, make early diagnoses, provide counseling for intervention of existing problems and referral to specialists when necessary [12].

\subsection{Significance of the Study}

Postpartum sexual health is a common issue that is often not discussed during prenatal or postpartum care and has received little attention from either health professionals or researchers. Although sexual dysfunctions could affect women in both pregnancy and postpartum period, as it showed significant changes in women's husbands and family lives [2]. Sexual problems affect about 20 to $73 \%$ of women in the world. Sexual dysfunctions resulting from changes in biological, psychological, social and cultural factors which lead to deterioration in desire, arousal and orgasm [24]; [34].

Also, the sexual function of women after delivery is worse when compared to what it used to be before delivery as the incidence of sexual dysfunction increases up to 34 to $91 \%$ in women in the postpartum period and seems to vary over a wide range [36]. As well as sexuality is considered a vital part of the quality of life and overall health. Consequentially, this study has been done to evaluate the effect of PLISSIT Model Sexual Counseling Program on sexual quality of life for postpartum women.

\subsection{Aim of the Study}

The aim of this study was to evaluate the effect of PLISSIT model sexual counseling program on sexual quality of life for postpartum women.

\subsection{Research Hypothesis}

PLISSIT Model sexual counseling program will be effective for improving sexual quality of life for postpartum women.

\section{Subjects and Methods}

\subsection{Research Design}

A quasi- experimental research design was utilized to conduct the study with pre/post program.

\subsection{Setting}

The study was conducted in Obstetrics and Gynecological Outpatient Clinic at Benha University Hospital.

\subsection{Subjects}

\subsubsection{Subject Type}

A purposive sample

\subsubsection{Subject Size}

All admitted postpartum women in the mentioned setting for a period of 6 months (110 postpartum women).

\subsubsection{Technique}

All admitted postpartum women who fulfil inclusion criteria and agree to participate in the study for a period of 6 months were included in the study (110 post-partum women). The researchers visit the previous setting 3 days per week until the pre-determined period is finished.

Inclusion Criteria:

1. Age 18-40.

2. Within 2-12 months of the postpartum period.

3. Women who don't have any chronic diseases may affect sexuality

\subsection{Tools of Data Collection}

Three tools were used by the researchers after extensive review of the related literature.

\subsubsection{First Tool}

A structured interviewing questionnaire: it designed by researchers after reviewing related literature and translated into Arabic language. It consisted of the following four parts:

Part I: Demographic characteristics of the women included (wife \& husband age, educational level of both, place of residence, wife $\&$ husband job, and family type).

Part 2: Obstetric history of the women included; duration 
of marriage, wife marriage age, mode of delivery, episiotomy with previous vaginal delivery, number of children, and frequency of pregnancy.

Part 3: Sexual problems history of the woman included: receiving information about sexuality, sexual problems before \&during pregnancy, painful during intercourse after labor, returning time of sexual life after labor.

Part 4: Current history of postpartum period which included; postpartum month, contraceptive method, breast-feeding, suffering from health problems\& economical stressors for both partner, her baby suffering from any health problems receiving helping from others in housekeeping and sleepiness with her baby.

\subsubsection{Second Tool}

Arizona Sexual Experience Scale: This scale was adopted from [2], modified and translated into Arabic language by the researchers for evaluating sexual malfunctions. It consists of 5 questions to determine painful during intercourse after labor, sexual desire, arousal \& vaginal wetness, the capacity to reach orgasm and the feeling of satisfaction after orgasm.

Scoring system:

There was four points Likert scale for each question, from 1 to 4 (very strong $=4$, somewhat strong $=3$, somewhat weak $=2$, very weak $=1$. Total score ranges from the sum of the scores obtained from the scale items, the total scale score was classified as the following:

1. Satisfactory: $\geq 60 \%$ of total score.

2. Unsatisfactory: $<60 \%$ of total score

\subsubsection{Third Tool}

The Sexual Quality Of Life-Female (SQOL-F) questionnaire:

It was developed by [30]: The SQOL-F questionnaire is a specific and self-report instrument that focuses on sexual selfesteem, emotional and relationship issues. It consists of 18 items such as thinking about sex life, sexual relation considers enjoyable part of overall life, feeling of frustration, depression, anexiety, loss of confidence and body image. And each item is rated on a three-point responses (completely agree $=3$, moderate $=2$ and completely disagree $=1$ ).

Scoring system:

The response categories scored from 1 to 3 score. Higher score indicates better female sexual quality of life. In addition, total score was converted into total percentage and graded as the following; if percentage of the total score more than $75 \%$ considered good, if percentage of the total score from $60-75 \%$ considered average, and considered poor if the percentage of total score is less than $60 \%$

\subsection{Methods}

The study was executed according to the following steps

\subsubsection{Approvals}

A written official approval to conduct this research was obtained from the director of Benha University hospital that was taken and delivered to the director of the Obstetrics and Gynecology Department, in order to obtain their agreement to conduct the study after explaining its purpose.

\subsubsection{Tools Validity and Reliability}

Content validity was done by panel expertise. The developed tool was reviewed for appropriateness of items and measuring the concepts by a jury of five experts in the field of maternity nursing and community health nursing specialty at Ain shams university and Mansoura University to assure content validity. The questionnaire was modified according to the panel judgment on the clarity of sentences and appropriateness of content. The reliability was done by Cronbach's Alpha coefficient test which revealed that each of the three tools consisted of relatively homogenous items as indicated by the moderate to high reliability of each tool was $(0.86)$.

\subsubsection{Ethical Considerations}

This study was conducted under the approval of the Faculty of Nursing Ethical Committee, Benha University. An official permission was obtained from the directors of the pre- mentioned setting. Each Participants were given explanations about the purpose of the study and was informed that participation is voluntary and they are free to withdraw from the study at any time before the completion of the study, those who agreed to complete in this study were asked to sign a consent form before starting the data collection. Confidentiality was ensured throughout the study process, and the women were assured that all data were used only for research purpose.

\subsubsection{The Pilot Study}

It represented $10 \%$ of the total sample (11 women) were recruited for the pilot study. It was conducted to assess tools clarity and applicability. It has served in estimating the time needed for filling the form of the study. It has also served in determining the needs of women which have been taken in consideration during developing the PLISSIT model sexual counseling program. These women are excluded from the study sample.

\subsubsection{Procedures}

- Official permissions were taken to carry out the study.

- Informed consents were obtained from selected subjects and the aim of the study was explained to them.

- The study was carried out from beginning of May 2017 till the end of October 2017 covering a period of 6 months.

\section{Preparatory Phase}

Preparation of the study design and data collection tools was based on reviewing current \& past, local and international related literature by using periodicals journal, magazines, books and computer search to construct the tool of the study. Also preparation of Sexual Counseling Program for Postpartum women, the content of this program was prepared based on [4] PLISSIT Model of Intervention related to the postpartum period was developed and converted into a beneficial booklet.

This study conducted through four sequential phases:

1- Assessment phase:

The researchers introduce themselves and explained the aim of the study, scheduled times and frequency of counseling sessions to all selected women to assure adherence to selected 
interventions. After the women gave both their verbal and written consent to the research, using a face-to-face interview technique, facilitated filling a structured interviewing questionnaires, Arizona sexual Experience Scale and sexual quality of life-female (SQOL-F) questionnaire. Data were collected through pre- test questionnaire related baseline data regarding postpartum period, sexual problems. Two scales (Arizona sexual Experience Scale and sexual quality of lifefemale (SQOL-F) questionnaire) were measured after application of PLISSIT Counseling Model intervention. The average time for the completion of questionnaires take from 25 to 30 minutes. A number of interviewed women / week ranged from 10-12 women.

\section{2- Planning phase:}

Based on pre-test assessment, the content of program regarding women's needs and management of postpartum sexual problems prepared by the researchers after reviewing related literature using the PLISSIT Model Counseling Program Construction through application of four levels permission $(\mathrm{P})$, limited information (LI), specific suggestions (SS), and intensive therapy (IT).

3- Implementation phase:

The counseling sessions were conducted in Obstetrics and Gynecological Outpatient Clinic at Benha University Hospital. The researchers visited the above mentioned setting from 9.00 am to $12.00 \mathrm{pm}$, three days / week by rotation (Saturday, Monday and Tuesday). A six counseling sessions, each session lasting around one hour for three weeks for each woman. The participated women received the counseling session individually. The researchers established the session's environment to be comfortable and quiet. They used a well prepared intervention materials and contents in the form of comprehensive illustrated booklet and educational videos related to the sexuality during postpartum period by using PLISSIT Model.

\section{Permission}

The first PLISSIT model level involves giving permission to post-partum women to discuss \& express feelings and concerns related to a specific health issue that they may affect post-partum period. By encouraging them to share their thoughts, questions, in a safe and comfortable environment and help to build a trusting relationship. At this level, reassuring studied women that plan to do is an appropriate course of action for their situation. At this step, the researchers asked an open -ended and general question such as: what has your experience been with sexual issues during postpartum period.

II. Limited Information

This is the second PLISSIT model level. The researchers offered brief information to the women to provide basic education about the sexual quality of life during post-partum period. In this stage, the researchers focused on addressing and correcting misconceptions regarding knowledge about the topic to answer women's questions.

III. Specific Suggestions

Through this level the researchers provided interventions to manage problems during post-partum period that had a great impact on sexual life. Firstly, the researchers collaboratively identified issues to be addressed with the women by using problem solving approach and choose helpful strategies that experienced personally and started to discuss. for example if a women expresses anticipatory anxiety about sexual intercourse with her husband for fear of pain or discomfort, the researchers addressed relaxation strategies including breathing exercise, distraction and recreation, appropriate healthy life style including healthy diet (high fiber diet, low fat diet, high vegetables/fruits diet, managing body image by _ Psychological counseling and support and physical activity including walking for at least 30 minutes / day. Also, performing shoulders range of motion exercise. This level of intervention must involve advanced knowledge and experience more thoroughly of a particular health issue and skill to assess a women's unique situation related to this health issue and to develop a plan.

IV. Intensive therapy

This fourth PLISSIT model level, where referral to a specialist may be required but a minority of women will require intensive therapy for a particular issue. In this stage, the researchers identified services to which women can be referred for more intensive or comprehensive care (social worker, sex therapist, psychological, and medical specialist)

4- Evaluation phase:

After implementation of PLISSIT Model counseling program, the researchers were used the same previous tools as Post-test such as SQOL-F questionnaire and Arizona sexual Experience Scale to evaluate the effect of PLISSIT Model sexual counseling program on sexual quality of life for postpartum women.

\subsubsection{Statistical Analysis}

Data were collected, entered and analyzed by using SPSS (version 20) software computer package (special package for social science). Presented in tabular form, Percentages were calculated for qualitative data and $\mathrm{x} 2$ for test of significance, mean and standard deviations were calculated for quantitative data Chi Square (X2), t-test, ANOVA (F test), paired t-test and correlation coefficient ( $\mathrm{r}$ ) were used when appropriate. P-value $<0.05$ was considered to be statistically significant.

\subsubsection{Limitation of the Study}

Some participated women withdrawn from the study after filling the interview questionnaire, because they considered the sexual issues are prevented to be discussed openly (culture issue).

\section{Results}

Table 1 shows that, $73.6 \%$ of studied women were from 20 to 30 years with the mean age $25.02 \pm 4.47$. Concerning educational level of them, $37.3 \%$ were had middle education. $70.9 \%$ of studied women were living in rural areas and $81.8 \%$ of women were housewives. Regarding family type, the results showed that $58.2 \%$ of studied women were related to nuclear family.

Table 2 shows that, the mean age of the husband was 
$38.30 \pm 6.42$ years, $43.6 \%$ of them aged more than 40 years. Regarding the job of husband, $87.3 \%$ of them were employed. Concerning the level of husband education, $60.9 \%$ of them were had middle education.

Table 3 illustrates distribution of studied sample regarding history of obstetrics. It was found that; $50 \%$ of women their marriage duration from one to five years with the Mean \pm SD $6.98 \pm 4.43$. Regarding marriage age; $59.1 \%$ of them were from 20 to 30 years with the Mean \pm SD $22.84 \pm 4.67$. Concerning pregnancy frequency $46.4 \%$ of them was pregnant for two times. $77.3 \%$ of them had one to three children. Regarding mode of delivery; $68.2 \%$ of them delivered CS and also $72.3 \%$ of women who delivered vaginally made episiotomy.

Table 4 illustrates women's sexual problems. It was found that; $85.5 \%$ of women did not receive information about sexuality, $(52.7 \%, 68.2 \%)$ of them had sexual problems before $\&$ during pregnancy respectively, $72.3 \%$ suffered from pain during intercourse after labor. $63.6 \%$ returned to sexual relation after six week of the labor with the Mean \pm SD $4.58 \pm 1.31$.

Table 5 reveals that; $83.6 \%$ of women were from two to six month postpartum and $58.2 \%$ of them lactate their children naturally, $48.2 \%$ of those used injection for contraception. Only $(12.7 \%, 6.4 \%)$ of the women and their husband suffered from health problems but $59.1 \%$ of them suffered from economic problems. $44.5 \%$ of those received helping from others in housekeeping. Results find that only; $23.6 \%$ of their children suffered from health problems and $89.1 \%$ of them sleeping with their children.

Table 6 shows that there were highly statistically significant differences between women regarding mean scores of Arizona Sexual Experiences Scale before and after the sexual counseling program $(p<0.001)$.

Table 7 shows that there were highly statistically significant differences between women before and after the sexual counseling program regarding all sexual quality of life items $(\mathrm{p}<0.001)$.

Figure 1 displays that only $13.6 \%$ of women had good total sexual quality of life before PLISSIT model counseling program, which increased to $44.5 \%$ after PLISSIT model counseling program. (29.1\% of) women had poor total sexual quality of life before PLISSIT model counseling program, which decreased to $5.5 \%$ after PLISSIT model counseling program. The figure shows significant improvement in sexual quality of life level after program implementation.

Table 8 demonstrates that, there was a positive statistically significant correlation between total Arizona Sexual Experiences Scale for studied sample' sexual functioning and their total sexual quality of life pre/post the PLISSIT model sexual counseling program.

Table 1. Frequency distribution of studied sample regarding their demographic characteristics $(n=110)$.

\begin{tabular}{lll}
\hline Demographic characteristics & No. & $\%$ \\
\hline Wife Age & & \\
$<20$ yrs. & 11 & 10.0 \\
20 to 30 yrs. & 81 & 73.6 \\
$>30$ yrs. & 18 & 16.4 \\
Mean \pm SD & $25.02 \pm 4.47$ & \\
\hline
\end{tabular}

\begin{tabular}{lll}
\hline Demographic characteristics & No. & \% \\
\hline Educational level & & \\
Don't read and write & 13 & 11.8 \\
Basic education & 38 & 34.5 \\
Middle education & 41 & 37.3 \\
High education & 18 & 16.4 \\
Residence & & \\
Rural & 78 & 70.9 \\
Urban & 32 & 29.1 \\
Wife job & & \\
Employ & 20 & 18.2 \\
Housewife & 90 & 81.8 \\
family type & & \\
Nuclear & 64 & 58.2 \\
Compound & 46 & 41.8 \\
\hline
\end{tabular}

Table 2. Frequency distribution of studied sample regarding demographic characteristics of their husband ( $n=110)$.

\begin{tabular}{lll}
\hline Items & No. & $\mathbf{\%}$ \\
\hline Husband age & & \\
$<30$ yrs. & 15 & 13.6 \\
30 to 40 yrs. & 47 & 42.7 \\
$>40$ yrs. & 48 & 43.6 \\
Mean \pm SD & $38.30 \pm 6.42$ & \\
Husband job & & \\
Employ & 96 & 87.3 \\
Not employ & 14 & 12.7 \\
Husband educational level & & \\
Don't read and write & 8 & 7.3 \\
Basic education & 20 & 18.2 \\
Middle education & 67 & 60.9 \\
High education & 15 & 13.6 \\
\hline
\end{tabular}

Table 3. Frequency distribution of studied sample regarding their obstetrics history $(n=110)$.

\begin{tabular}{lll}
\hline Items & No. & \% \\
\hline Marriage duration & & \\
1 to 5yrs. & 55 & 50.0 \\
6 to10 yrs. & 35 & 31.8 \\
Less than10 yrs. & 20 & 18.2 \\
Mean \pm SD & $6.98 \pm 4.43$ & \\
Wife marriage age & & \\
Less than 20 & 10 & 9.1 \\
From 20 to 30 & 65 & 59.1 \\
More than 30 & 35 & 31.9 \\
Mean \pm SD & $22.84 \pm 4.67$ & \\
Pregnancy frequency & & \\
Once & 27 & 24.5 \\
Twice & 51 & 46.4 \\
Three & 21 & 19.1 \\
Four or more & 11 & 10.0 \\
Children number & & \\
1 to 3 child & 85 & 77.3 \\
4 or more child & 25 & 22.7 \\
Mode of delivery & & \\
Vaginal delivery & 35 & 31.8 \\
Caesarean section & 75 & 68.2 \\
Episiotomy & & \\
Yes & 30 & 72.3 \\
No & 80 & \\
\hline
\end{tabular}

Table 4. Frequency distribution of studied sample regarding sexual problems $(n=110)$.

\begin{tabular}{lcc}
\hline Items & No. & \% \\
\hline Received information about sexuality & & \\
Yes & 16 & 14.5 \\
\hline
\end{tabular}




\begin{tabular}{lll}
\hline Items & No. & \% \\
\hline No & 94 & 85.5 \\
Sexual problems before pregnancy & & \\
Yes & 58 & 52.7 \\
No & 52 & 47.3 \\
Sexual problems during pregnancy & & \\
Yes & 75 & 68.2 \\
No & 35 & 31.8 \\
Painful during intercourse after labor & & \\
Yes & 80 & 72.3 \\
No & 30 & 27.3 \\
Time of return to sexual life, day after labor & & \\
2 week. & 7 & 6.4 \\
4 week. & 33 & 30.0 \\
6 week or more & 70 & 63.6 \\
Mean \pm SD & $4.58 \pm 1.31$ & \\
\hline
\end{tabular}

Table 5. Frequency distribution of studied sample regarding post-partum period $(n=110)$.

\begin{tabular}{lcc}
\hline Items & No. & \% \\
\hline Post-partum month & & \\
From 2 to 6 & 92 & 83.6 \\
More than 6 & 18 & 16.4 \\
Breast feeding & & \\
Yes & 64 & 58.2 \\
No & 46 & 41.8 \\
Contraceptive method & & \\
\hline
\end{tabular}

\begin{tabular}{lll}
\hline Items & No. & \% \\
\hline Not used & 12 & 10.9 \\
Intrauterine device & 33 & 30.0 \\
Injection & 53 & 48.2 \\
Pills & 12 & 10.9 \\
Suffering from health problems & & \\
Yes & 14 & 12.7 \\
No & 96 & 87.3 \\
Suffering from economical stresses & & \\
Yes & 65 & 59.1 \\
No & 45 & 40.9 \\
The husband suffering from health problems & & \\
Yes & 7 & 6.4 \\
No & 103 & 93.6 \\
Others helping you in house keeping & & \\
Yes & 49 & 44.5 \\
No & 61 & 55.5 \\
Child suffering from health problem & & \\
Yes & 26 & 23.6 \\
No & 84 & 76.4 \\
Sleeping the woman with her child & & \\
Yes & 98 & 89.1 \\
No & 12 & 10.9 \\
\hline
\end{tabular}

Table 6. Mean scores of Arizona Sexual Experiences Scale for studied sample pre \& post the PLISSIT model sexual counseling program ( $n=110)$.

\begin{tabular}{lllll}
\hline \multirow{2}{*}{ Items } & Pre & Post & t* & p-value \\
\cline { 2 - 5 } & $\mathbf{X}^{*} \pm$ SD & & & \\
\hline Painful during intercourse after labor? & $3.48 \pm 0.67$ & $1.46 \pm 0.68$ & 17.053 & .000 \\
How strong is your sex drive? & $1.60 \pm 0.69$ & $3.21 \pm 0.80$ & 14.282 & .000 \\
How you are sexually aroused (turned on)? & $1.60 \pm 0.67$ & $3.21 \pm 0.94$ & 18.605 & .000 \\
Vagina becomes moist or wet during sex? & $1.49 \pm 0.60$ & $3.20 \pm 0.74$ & 15.152 & .000 \\
Can you reach an orgasm? & $1.69 \pm 0.57$ & $3.19 \pm 0.80$ & 18.365 & .000 \\
\hline
\end{tabular}

$\mathrm{t} *$ Paired $\mathrm{t}$ test

A highly statistical significant difference $(\mathrm{P} \leq 0.001)$

Table 7. Percentage distribution of studied sample regarding sexual quality of life pre \& post the PLISSIT model sexual counseling program ( $n=110$ ).

\begin{tabular}{|c|c|c|c|c|c|c|c|c|}
\hline Items & Pre & & & Post & & & & \\
\hline When I think about my sex life & Agree & Moderate & Disagree & Agree & Moderate & Disagree & $\mathbf{X} 2$ & p-value \\
\hline It is an enjoyable part of my overall life. & 24.5 & 30.0 & 45.5 & 91.8 & 4.5 & 3.6 & 102.5 & 0.000 \\
\hline 2. I feel frustrated. & 27.3 & 42.7 & 30.0 & 9.1 & 32.7 & 58.2 & 21.36 & 0.000 \\
\hline 3. I feel depressed.. & 30.0 & 56.4 & 13.6 & 6.4 & 35.5 & 58.2 & 52.53 & 0.000 \\
\hline 4. I feel like less of awoman & 22.7 & 41.8 & 35.5 & 8.2 & 38.2 & 53.6 & 12.08 & 0.007 \\
\hline 5. I feel good about my self & 10.0 & 20.0 & 70.0 & 80.9 & 12.7 & 6.4 & 124.1 & 0.000 \\
\hline 6. I feel anaxious. & 40.0 & 50.0 & 10.0 & 6.4 & 37.3 & 56.4 & 64.51 & 0.000 \\
\hline 7. I have lost confidence in my self as a sexual partner. & 27.3 & 46.4 & 26.4 & 11.8 & 30.9 & 57.3 & 22.68 & 0.000 \\
\hline 8. I feel angered. & 20.9 & 45.5 & 33.6 & 7.3 & 32.7 & 60.0 & 17.7 & 0.000 \\
\hline 9. I feel close to my partner. & 36.4 & 47.3 & 16.4 & 80.0 & 15.5 & 4.5 & 43.1 & 0.000 \\
\hline 10. I worry about the future of my sex life. & 33.6 & 51.8 & 14.5 & 5.5 & 45.5 & 49.1 & 43.4 & 0.000 \\
\hline 11. I have lost pleasure in sexual activity. & 43.6 & 39.1 & 17.3 & 7.3 & 42.7 & 50.0 & 46.3 & 0.000 \\
\hline 12. I feel embarrassed. & 41.8 & 41.8 & 16.4 & 6.4 & 46.4 & 47.3 & 45.4 & 0.000 \\
\hline $\begin{array}{l}\text { 13. I feel that I can talk to my partner about sexual } \\
\text { matters. }\end{array}$ & 12.7 & 36.4 & 50.9 & 71.8 & 20.9 & 7.3 & 86.0 & 0.000 \\
\hline 14. I try to avoid sexual activity. & 36.4 & 45.5 & 18.2 & 9.1 & 40.0 & 50.9 & 35.4 & 0.000 \\
\hline 15. I feel guilty. & 24.5 & 62.7 & 12.7 & 3.6 & 38.2 & 58.2 & 55.6 & 0.000 \\
\hline 16. I worry that my partner feels hurt or rejected. & 40.9 & 58.2 & .9 & .9 & 43.6 & 55.5 & 102.4 & 0.000 \\
\hline 17. I feel like I have lost something. & 41.8 & 55.5 & 2.7 & & 39.1 & 60.9 & 107.6 & 0.000 \\
\hline 18. I satisfied with the frequency of sexual activity. & 6.4 & 43.6 & 50.0 & 67.3 & 15.5 & 17.3 & 87.7 & 0.000 \\
\hline
\end{tabular}

A highly statistically significant $(\mathrm{P} \leq 0.001)$ 


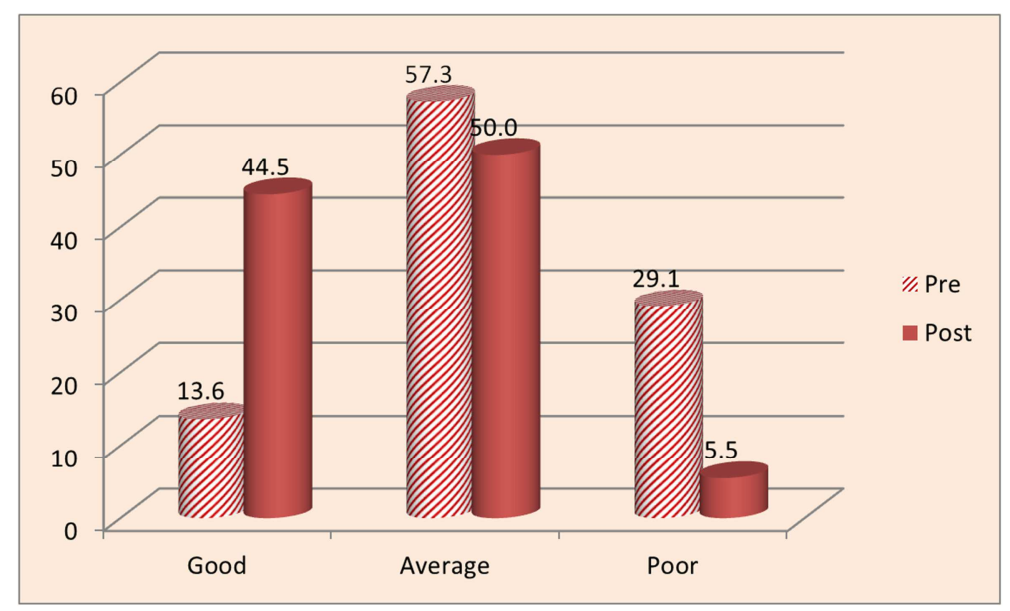

Figure 1. Percentage distribution of studied women regarding total quality of life score pre \& post the PLISSIT model sexual counseling program.

Table 8. Correlation coefficient between total Arizona Sexual Experiences Scale for studied sample' sexual functioning and their total sexual quality of life pre \& post the PLISSIT model sexual counseling program.

\begin{tabular}{lllll}
\hline & \multicolumn{3}{l}{ Total quality } & \\
\cline { 2 - 5 } & Pre & & Post & \\
\cline { 2 - 5 } & $\mathbf{r}$ & p-value & r & p-value \\
\hline Arizona & 0.45 & 0.03 & 0.68 & 0.0000 \\
\hline
\end{tabular}

(r) * correlation coefficient.

\section{Discussion}

Childbirth is a challenging experience for mothers. Women during postpartum period are challenged by many psychological, physical and socio-cultural factors which affect their quality of life and sexual health. The World Health Organization on postpartum care guide of the mother and newborn recommended that education and counseling on sexual life is identified as one of the women' needs as postpartum time represents an ideal opportunity to address sexual health existing problems [35].

The aim of the current study was to evaluate the effect of PLISSIT model sexual counseling program on sexual quality of life for postpartum women.

Regarding demographic characteristics of the studied sample, the results revealed that; most of studied women were from 20 to 30 years with the mean age $25.02 \pm 4.47$. Concerning educational level of them, more than one-third were had middle education. More than two-thirds of studied women were living in rural areas and the majority of women were housewives. These findings in agreement with [27] who reported, majority of the women were between 20 and 30 years of age, the vast majority were house wives and around two-thirds of studied women were had middle education. This low education level may be the cause for avoiding discussion about sexual issues. More than half of the studied women were related to nuclear families. This similar to the findings of [36] reported that the majority of subjects were living in nuclear families.

Concerning demographic characteristics of the husband, the current study showed that, more than one-third of husbands aged more than 40 years with mean age $38.30 \pm$ 6.42 , most of them were employed and more than half had middle education. This similar to [23] found that one third of the spouses aged from 40 to 49 years with mean age $46.71 \pm 8.71$ years. Also [6] found the highest percentage of spouses had secondary education and employed.

The study findings regarding studied women obstetric history revealed that, around half were pregnant for two times. This finding incongruent with [5] they found that more than one-third of participants were had one pregnancy. Also, disagreed with [22] who reported that, more than half of study sample were primiparous.

More than two-thirds of studied women delivered Caesarean Section. This result in line with [25] who found type of delivery in $(61.3 \%)$ of cases was caesarean. More than three quarters of women under study had one to three children More than two-thirds of women made episiotomy with vaginal delivery. In the same line with [18] who found that almost all the studied participants had one to three children and $(80.3 \%)$ of full term vaginal delivery women had episiotomy. From the point of the researcher, several problems associated with caesarean section and episiotomy such as perennial pain and weakness of pelvic floor muscles mainly affect the return to normal sexual life postnatal.

The present study findings regarding studied women sexual problems indicated that, the majority of women did not receive information about sexuality. This may reflect their need for guidance and consultation regarding sexual health issues. This result agreed with [8] who studied "the effect of mode of delivery on postpartum sexual function and sexual quality of life in primiparous women" who reported that majority of subjects need sexual issues consultation.

More than half of women had sexual problems before pregnancy increased to more than three quarters during pregnancy. In agreement with [15], they reported, the participants' sexual dysfunction identified before pregnancy was $33.5 \%$, increased to $76.0 \%$ during pregnancy. This reflected the importance of manipulating women sexual health and sexual problems as it considered a public health problem which affects most women before \& during pregnancy and continues to postnatal period. 
The present study results showed that, nearly two-thirds of women returned to sexual relation after six weeks of the labor. This finding consistent with [8] who illustrated that three quarters of studied groups were resumed sexual intercourse sixth week after delivery. Also supported by [3], who reported that, more than half of studied women had resumed sexual intercourse by six weeks postpartum. While incongruent with [11], who found that, the studied women reassumed sexual activity from eight weeks to twelve months. These differences in resumption of postpartum sexual intercourse may be attributed to diverse cultural backgrounds, beliefs, religious practices and sexual concerns of women in different parts of the world. Most of studied sample suffered from pain during intercourse after labour. This finding in agreement with [11], who stated that, most of participants $(78.7 \%)$ had dyspareunia or pain during intercourse after delivery. On the other hand, in contrast with [21], who found that slightly more than one-quarter of women complain dyspareunia.

On regard to studied women' postpartum period; Around four-fifth of women were in two to six month postpartum, similar to [6] they conducted a study about " Impact of counseling on sexual intimacy of lactating women" revealed that, mean postpartum duration of studied women was $3.56 \pm 1.58$ months. More than half of studied women lactate their children naturally, this finding consistent with [32], who found that the majority of women breastfed their neonates. Also nearly half of women used intra uterine device for contraception. Similar to [21], reported that nearly half of women with dyspareunia used intrauterine device as a contraceptive method. Also, supported by [16] who concluded, that the highest percentage of women were using mechanical methods for contraception.

Minority of studied women and their husbands had health problems while the majority of women sleeping with their children, similar to a study about " Sexual problems in women during the first postpartum year and related conditions" conducted by [2] they revealed that $10.4 \%$ of the studied women and $5.7 \%$ spouses had health problems while $71.3 \%$ of them reported that they were sleeping in the same room with their babies. The current study findings illustrated that, there were highly statistical significant differences between women regarding mean scores of Arizona Sexual Experiences Scale before and after the PLISSIT Model sexual counseling program. This finding approved by [36], who stated that, before the application of the PLISSIT Model intervention, most of women were facing sexual problems according to the Arizona Sexual Experiences Scale. However, after the application of the PLISSIT Model, a lesser proportion of the women were facing sexual problems. This difference was significant to the statistical analysis. Moreover, this result supported by [31], who found that, sexual problems in lactating women decreased by using the PLISSIT model. Also, [29] reported that sexual-counseling strategies can be used by the health care providers to assist them in gradual discussing the topic of sexual health and providing supportive counseling and intervention. In the same line results of [23], indicated that the sexual health enhancement program is effective in improving sexual function. [28], revealed that a post-intervention improvement in all the dimensions of sexual functioning.

As regards studied sample sexual quality of life, the current study showed that, there were highly statistical significant differences between women before and after the PLISSIT model sexual counseling program regarding all sexual quality of life items $(p<0.001)$ where, only less percentage of women had good total sexual quality of life before PLISSIT model counseling program, which increased significantly after PLISSIT model counseling program. This result was supported by [9], they found that, the mean quality of sexual life was $41.8 \pm 5.0$ in the intervention group before PLISSIT-based sexual rehabilitation, and reached 53.1 \pm 5.8 after the rehabilitation. There was a significant increase in the mean quality of sexual life in post-mastectomy women following the PLISSIT-based intervention.

The present study revealed that there was a positive statistically significant correlation between total ASEX score and total sexual quality of life. This reflected that improvement in sexual function which resulted in sexual quality of life improvement. In agreement with [25], who reported that, women with higher sexual function scores had significantly better quality of life in all aspects including sexual quality of life. Also, similar to a study conducted in Malaysia by [14], revealed that sexual dysfunction had a significant impact on the wellbeing and sexual health of women. Furthermore, [33] studied "sexual functioning and quality of life of women with opioid dependence, revealed significant correlation between quality of life and sexual functioning.

\section{Conclusion}

Based on the findings of the current study; the study concluded that research hypothesis is supported and the PLISSIT model sexual counseling program had a significant effect on improvement of postpartum women' sexual function and sexual quality of life. There was a positive statistically significant correlation between total Arizona Sexual Experiences Scale for studied subjects' sexual health and their total sexual quality of life before \& after the PLISSIT model sexual counseling program.

\section{Recommendations}

1- Prepare a safe environment in the obstetrics and gynecological outpatient unit to discuss sexual problems with women freely by using PLISSIT model directed towards sexual problems encountered during the postpartum period.

2- Establish strategies to facilitate the women's understanding and support sexual quality of life through apply this study on a large sample at outpatient clinics. 


\section{Future Researches}

1. Nurses should provide education and counseling sessions for postpartum women to promote sexual health and sexual quality of life.

2. Sexual health should be included in the Ministry of Health and Population plan to care for women after childbirth.

\section{Acknowledgements}

The researchers would like to express gratitude and appreciations to the women who participated in this study for their effective cooperation.

\section{References}

[1] Abdool Z, Thakar R, Sultan AH, (2016): Postpartum female sexual function. European Journal of Obstetrics \& Gynecology and Reproductive Biology: 145 (2): 133-137.

[2] Acele EO \& Karaçam Z. (2012): Sexual problems in women during the first postpartum year and related conditions. J Clin Nurs. 21 (7-8):929-37.

[3] Alum, A., Kizza, I., Osingada, C., Katende, G., \&Kaye, D. (2015): Factors associated with early resumption of sexual intercourse among postnatal women in Uganda. Report Health; 12: P. 107.

[4] Annon JS. (1981): The PLISSIT model: a proposed conceptual scheme for the behavioral treatment of sexual problems. J Sex Educ; 2: Pp. 1-15.

[5] Anzaku, A., and Mikah, S. (2014): Postpartum resumption of sexual activity, sexual morbidity and use of modern contraceptives among Nigerian women, Ann Med Health Sci Res.; 4 (2): Pp. 210-216.

[6] Banaei, M., Zahrani, Sh., Pormehr-Yabandeh, A., Ozgoli, G., and $\mathrm{Azad}, \mathrm{M}$. (2016): Investigating the impact of counselling based on PLISSIT model on sexual intimacy and satisfaction of breastfeeding women, International Journal of Pharmaceutical Research \& Allied Sciences; 5 (3): pp. 489499.

[7] Brtnicka H, Weiss P, Zverina J (2016): Human sexuality during pregnancy and the postpartum period. Bratislavské lekárske listy - Bratislava Medical Journal 110 (7): 427-431.

[8] Elsayed, H., Ramadan, S., Ibrahim, H., and Moursi, H. (2016): The Effect of Mode of Delivery on Postpartum Sexual Function and Sexual Quality of Life in Primiparous Women, American Journal of Nursing Science; 6 (4): Pp. $347-$ 357.

[9] Faghani, S., \& Ghaffari, F. (2016): Effects of Sexual Rehabilitation Using the PLISSIT Model on Quality of Sexual Life and Sexual Functioning in Post-Mastectomy Breast Cancer Survivors, Asian Pacific Journal of Cancer Prevention; 17 (11): P. 4849.

[10] Farnam F, Janghorbani M, Raisi F, Merghati-Khoei E. (2014): Compare the effectiveness of PLISSIT and sexual health models on Women's sexual problems in Tehran, Iran: a randomized controlled trial. J Sex Med. [PubMed] 139-146.
[11] Fodstad, K., Staff, A., and Laine, K. (2016): Sexual activity and dyspareunia the first year postpartum in relation to degree of perineal trauma, Available@ https://www.duo.uio.no/bitstream/handle.

[12] Glazener CMA. (2011): Sexual function after childbirth: women's experiences, persistent morbidity and lack of professional recognition. Br J Obstet. Gynaecol; 104: 330 333.

[13] Greenshields W, \& Hulme H. (2012): The Perineum in Childbirth. A Survey of women's experiences and midwives' practices: London: National Childbirth Trust, 1-95.

[14] Hassan, J., Lin, T., Sulaiman, S., and Darus, A. (2013): The prevalence of sexual dysfunction among female in a tertiary hospital in Malaysia, Available@ http://repository.um.edu.pdf.

[15] Holanda, J., Abuchaim, E., Coca, K., and Abrao, A. (2014): Sexual dysfunction and associated factors reported in the postpartum period, Brazil, Acta. Paul Enferm.; 27 (6):Pp. 573578 .

[16] Khajehei, M. (2013): Sexual function of women during the first year after childbirth: Effect of parity (giving birth after the 20th week of pregnancy), depression and relationship satisfaction, Doctorate thesis, Curtin University, P. 81.

[17] Kitzinger S. (2014): Chapter 13: sex. In: The Year after Childbirth: Surviving the First Year of Motherhood. Oxford: Oxford University Press,: 243-261.

[18] Leal, I., Lourenço, S., Oliveira, R., Carvalheira, A., and Maroco, J. (2014): Sexual function in women after delivery: Does episiotomy matter?, Health journal; 6 (5): pp. 356-363.

[19] Lee J-T\&Tsai J-L (2012) Trans theoretical model-based postpartum sexual health education program improves women's sexual behaviors and sexual health. The Journal of Sexual Medicine 9 (4): 986-996.

[20] Leeman LM, Rogers RG. (2012): Sex after childbirth: postpartum sexual function. Obstet Gynecol.; 119 (3):647-55.

[21] Mansour, S., Shebl, A., and Waheda, S. (2014): The Effect Of Sexual Counseling Program On Pain Level And Sexual Function Among Women With Dyspareunia, Egypt, Journal of Education and Practice; 5 (3): Pp. 208-220.

[22] Mousavi, S., Mortazavi, F., Chaman, R. and Khosravi, A. (2013): Quality of Life after Cesarean and Vaginal Delivery, Oman, Oman Medical Journal; 28 (4):Pp. 245-251.

[23] Nho, J. (2013): Effect of PLISSIT Model Sexual Health Enhancement Program for Women with Gynecologic Cancer and Their Husbands, J Korean Acad. Nurs.; 43 (5): pp. 681689 .

[24] Prado DS, Mota VP, Lima TI. (2010): Prevalence of sexual dysfunction in two women groups of different socioeconomic status. Rev Bras Gynecol. Obstet.; 32 (3):139-43. Portuguese.

[25] Rezaei, N., Omidi, F., Janani, F., and Azadi, A. (2017): A Study on the Relationship between Sexual Function and Quality of Life in Postpartum Women, Iran, Der Pharmacia Lettre; 9 (7): Pp. 10-17.

[26] Rostamkhani F, Ozgoli G, Khoei EM, Jafari F, Majd HA. (2012): Effectiveness of the PLISSIT-based Counseling on sexual function of women. J Nurs Midwifery.; 22:76. 
[27] Rostamkhani, F., Jafari, F., Ozgoli, G., and Shakeri, M. (2015): Addressing the sexual problems of Iranian women in a primary health care setting: A quasi-experimental study, Iranian Journal of Nursing and Midwifery Research; 20 (1):pp. 139-146.

[28] Saboula, N., and Shahin, M. (2015): Effectiveness of Application of PLISSIT Counseling Model on Sexuality for Breast Cancer's Women Undergoing Treatment, Egypt, American Journal of Nursing Science; 4 (4): Pp. 218-230.

[29] Sung, S., Jeng, Ch., and Lin, Y. (2011): Sexual health care for women with dyspareunia, Taiwan, Taiwanese Journal of Obstetrics \& Gynaecology; 50: Pp. 268-274.

[30] Symonds T, Boolell M, Quirk F (2005): Development of questionnaire on sexual quality of life in women. Journal of Sex \& Marital Therapy 31 (5): 385-397.

[31] Torkzahrani, Sh., Banaei, M., Ozgoli, G., Azad, M., and Mahmoudikohani, F. (2016): The effectiveness of consultation based on PLISSIT Model on sexual function of lactating women, Iran, The J Urmia Nurs Midwifery Fac,; 14 (7): Pp. 639-646.

[32] Valadan, M., Shariat, M., Rezaei, Z., Hagholahi, F.,
Sheikholeslami, G., and Bandegi, P. (2014): A comparative study on quality of life and sexual function after vaginal delivery and Cesarean section, Nurs Pract Today; 1 (4): pp. 176-182.

[33] Varma, A., Sethi, R., Hartman, DW., Herbertson, R., \& Kablinger, A. S., et al. (2014): Sexual Functioning and Quality of Life of Women with Opioid Dependence Maintained on Buprenorphine/Naloxone vs. Community Norms. J Subst.

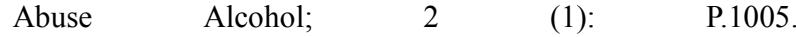
Available@:https://www.jscimedcentral.com.

[34] Vettorazzi J, Marques F, Hentschel H, Ramos JGL, MartinsCosta SH, Badalotti M. (2012): [Sexuality and the postpartum period: a literature review]. Rev HCPA.; 32 (4):473-9. Portuguese.

[35] World Health Organization (2014): WHO recommendations on Postnatal care of the mother and newborn, Available @ http://apps.who.int/iris /bitstream/_eng.pdf, Accessed on January 2018.

[36] Yörük F. \& Karaçam Z. (2016): The Effectiveness of the PLISSIT Model in Solving Postpartum Sexual Problems Experienced by Women, Athens Journal of Health.; 3 (3):235237. 